\title{
DINÂMICA INOVATIVA NOS ASSENTAMENTOS DA AMAZÔNIA: CONSIDERAÇÕES SOBRE O PROJETO DE DESENVOLVIMENTO SUSTENTÁVEL BONAL, SENADOR GUIOMARD - AC
}

\author{
INNOVATIVE DYNAMICS IN SETTLEMENTS OF THE AMAZON: CONSIDERATIONS \\ ABOUT THE PROJECT SUSTAINABLE DEVELOPMENT BONAL, SENADOR GUIOMARD- \\ $A C R E$
}

Paulo Alves da Silva ${ }^{1}$

Raimundo Cláudio Gomes Maciel $^{2}$

Pedro Gilberto Cavalcanti Filho ${ }^{3}$

\begin{abstract}
RESUMO
O desenvolvimento e a viabilidade da agricultura familiar ao longo do tempo tem sido alvo de intensos debates em torno de temas como a reforma agrária de determinadas regiões e a capacidade de reprodução social no campo. Recentemente vários assentamentos rurais foram implantados no Brasil, buscando-se encaminhar tais discussões no contexto do desenvolvimento sustentável. O objetivo geral do presente estudo é avaliar a dinâmica inovativa e o investimento no Projeto de Desenvolvimento Sustentável Bonal, Senador Guiomard, Acre. Trabalha-se com indicadores específicos de avaliação da produção familiar rural. Os resultados indicam baixa incidência de efetivos agricultores familiares, bem como uma propensão negativa a investir entre a maioria das unidades produtivas.
\end{abstract}

Palavras-chave: Agricultura Familiar. Investimento. Dinâmica Inovativa. Reforma Agrária. Amazônia.

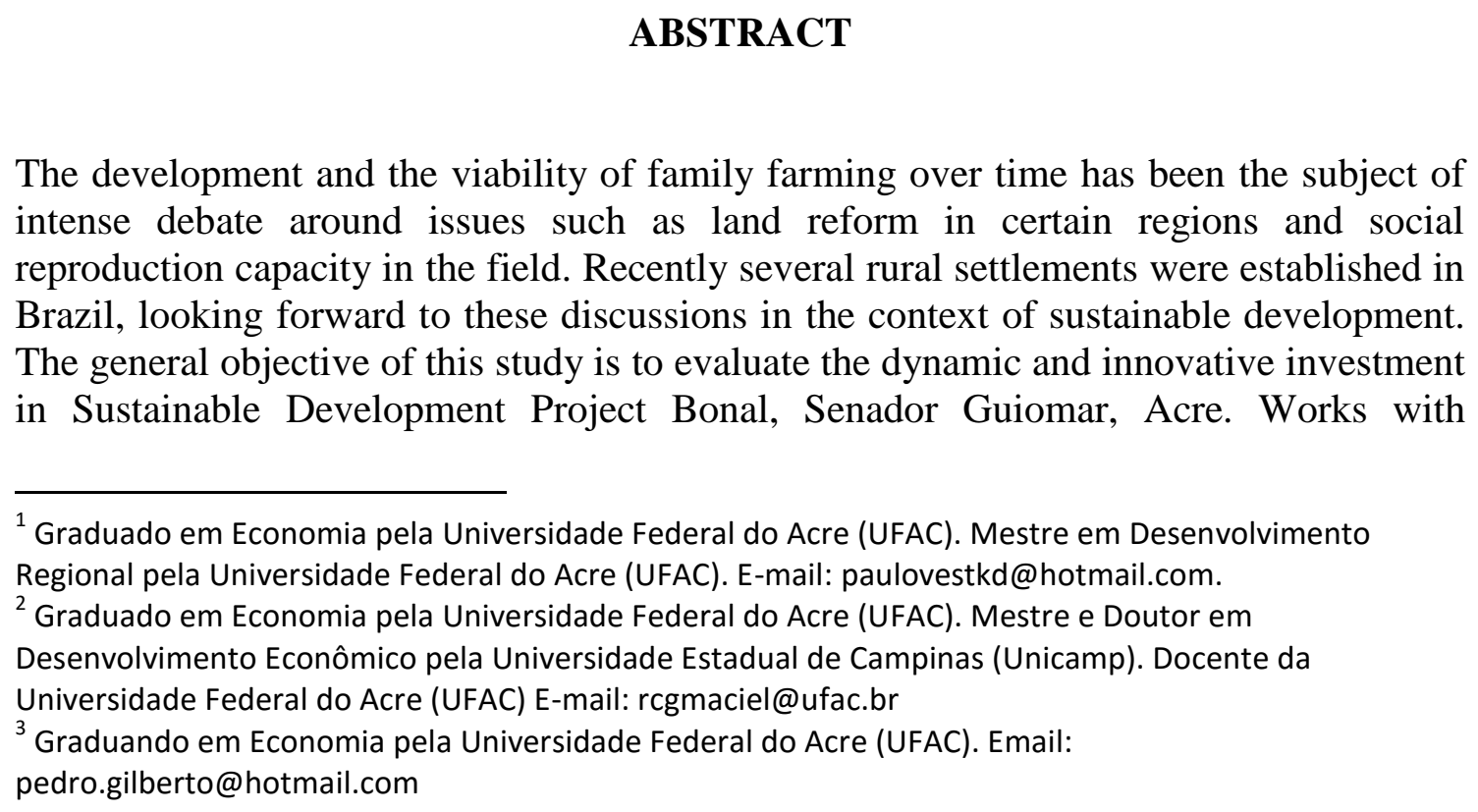

ABSTRACT

The development and the viability of family farming over time has been the subject of intense debate around issues such as land reform in certain regions and social reproduction capacity in the field. Recently several rural settlements were established in Brazil, looking forward to these discussions in the context of sustainable development. The general objective of this study is to evaluate the dynamic and innovative investment in Sustainable Development Project Bonal, Senador Guiomar, Acre. Works with

\footnotetext{
${ }^{1}$ Graduado em Economia pela Universidade Federal do Acre (UFAC). Mestre em Desenvolvimento Regional pela Universidade Federal do Acre (UFAC). E-mail: paulovestkd@hotmail.com.

${ }^{2}$ Graduado em Economia pela Universidade Federal do Acre (UFAC). Mestre e Doutor em Desenvolvimento Econômico pela Universidade Estadual de Campinas (Unicamp). Docente da Universidade Federal do Acre (UFAC) E-mail: rcgmaciel@ufac.br

${ }^{3}$ Graduando em Economia pela Universidade Federal do Acre (UFAC). Email: pedro.gilberto@hotmail.com
} 
specific indicators for assessing rural family production. The results indicate a low incidence of actual farmers, as well as a negative propensity to invest among the most productive units.

Keywords: Family Farming. Investment. Innovative Dynamics. Agrarian Reform. Amazon.

JEL: Q ; Q15

\section{Introdução}

No estado do Acre, a implantação dos projetos de colonização se intensifica na década de 70, com a decadência da produção de borracha e o incentivo dos governos estadual e federal à ocupação produtiva da Amazônia. Os créditos subsidiados aliados aos baixos preços das terras na região atraíram investidores do Sul e Sudeste brasileiro, que desenvolveram especialmente a pecuária extensiva.

Esse processo desencadeou uma série de conflitos sociais, notadamente na luta pela posse da terra, e ambientais - decorrentes dos desflorestamentos - na região, em particular no Acre. Nesse processo, a criação do Instituto Nacional de Colonização e Reforma Agrária (INCRA) foi fundamental para o encaminhamento de políticas de colonização voltadas à criação dos Projetos de Assentamentos Dirigidos (PAD's), direcionados à agricultura familiar, funcionando como áreas de acolhimento dos produtores rurais que estavam em zonas de conflitos em todo o país.

O desenvolvimento e a consolidação dos assentamentos na região acreana levaram a imensas dificuldades para a reprodução dos agricultores assentados, decorrentes de diversas questões como infraestrutura, crédito, assistência técnica etc. Tais questões, aliado à emergência da discussão do desenvolvimento sustentável levaram à criação de novos assentamentos, por exemplo, os Projetos de Desenvolvimento Sustentável (PDS).

No ano de 2005, após a aquisição da Fazenda Bonal, o INCRA instalou o assentamento PDS Bonal, no município de Senador Guiomar-Acre, para atender as famílias que residiam e trabalhavam na antiga fazenda. $\mathrm{O}$ assentamento foi considerado como um modelo de assentamento rural, tendo em vista a infraestrutura consolidada que havia: ramais trafegáveis, energia elétrica, plantios consolidados e até uma agroindústria de processamento de palmito instalada na área. 
Diante disso, o presente estudo buscou verificar se as famílias do PDS Bonal apresentam capacidade de investimento suficiente para dinamizar a produção para garantir o seu desenvolvimento no campo e, principalmente, sua reprodução social.

Este estudo busca investigar se as famílias do PDS Bonal têm capacidade de investimento suficiente para dinamizar a produção e garantir sua reprodução social.

Dessa forma, o objetivo deste trabalho é avaliar a dinâmica inovativa nas estratégias de reprodução das famílias no PDS Bonal, Senador Guiomard-Acre, no período agrícola de 2011/2012. Para avaliar a dinâmica é necessária a definição das características socioeconômicas e do perfil dos assentados.

A hipótese adotada para nortear o presente trabalho foi que os assentados do PDS Bonal, por não apresentarem características de produtores familiares, não possuem capacidade de investimento para dinamizar sua produção e garantir a reprodução social.

A importância do estudo justifica-se pela necessidade de encontrar políticas adequadas para as famílias assentadas na região, uma vez que se trata de um assentamento que foi implantado como um novo modelo. Entretanto, devido aos problemas gerenciais, produtivos e ausência do poder público para subsidiar medidas que amenizassem os problemas do assentamento, o PDS Bonal entrou em decadência, principalmente, após o fechamento da agroindústria e a falência da cooperativa.

\section{AGRICULTURA FAMILIAR, REFORMA AGRÁRIA E FINACIMENTO NA AMAZÔNIA}

Segundo Wanderley (2001), a agricultura familiar é caracterizada quando a família é a proprietária dos meios de produção e assume o trabalho nas unidades produtivas. Assim, todas as técnicas utilizadas na produção são definidas pelos próprios produtores rurais, os quais se utilizam de seus conhecimentos tradicionais para determinar todo sistema produtivo, desde a plantação até a comercialização do produto final.

$\mathrm{Na}$ primeira metade dos anos de 1990 é que a agricultura familiar, como expressão da agenda nacional, adentrou o cenário político. Até então, este agrupamento de estabelecimentos de menor escala recebia expressões, como minifundiários, pequenos produtores, agricultores de subsistência ou, como era corriqueiro na década de 1970, agricultores de baixa renda. A atividade econômica destes produtores, na 
literatura, quase sempre foi denominada de pequena produção. Camponeses foi palavra apenas ocasionalmente empregada em documentos de vulgarização, e não pelos próprios produtores (NAVARRO, 2010; FAVARETO, 2007).

Segundo Guimarães (1982), a evolução da agricultura realiza-se através de dois caminhos: ou pelo caminho democrático da distribuição da propriedade da terra e dos demais meios de produção entre a maioria da população rural, ou seja, pela reforma agrária; ou pelo caminho autocrático da transformação de terras improdutivas em grandes empresas rurais privadas, isto é, por uma política concentracionista da propriedade agrária, dos demais meios de produção e da renda.

As estruturas agrárias são caracterizadas como objeto de observação para a análise dos mecanismos de dominação social em que se baseia a extração autoritária de um excedente. Com efeito, uma estrutura agrária é apenas um conjunto de relações entre a população rural, a terra que ela trabalha e o produto desse trabalho (FURTADO, 2000).

Abramovay (2005) afirma que a distribuição de terras é um meio de ação contra a pobreza, a qual está fundamentada através do clamor de justiça, como também se sustenta através da questão de sobrevivência econômica das famílias: unidades produtivas ao alcance das capacidades de trabalho de uma família podem afirmar-se economicamente e ser, portanto, um fator de geração sustentável de renda. É claro que são fundamentais outros fatores como as condições de acesso a mercados dinâmicos, a crédito, a informações, a educação e a tecnologias.

A reforma agrária é um processo de transformação socioeconômica que envolve um grande esforço para incorporar o rural exluído dentro da sociedade através de mudanças radicais nas estruturas de propriedade, posse e acesso aos meios de produção. Assim, qualquer reforma envolve algum grau de profunda privação dos setores de proprietários, pois enfraquece as bases de seu poder econômico e político (OSZLAK, 1971; tradução livre).

Melo (2006) afirma que durante o governo militar a promulgação da emenda constitucional $n^{\circ} 10$, em 09/11/1964, que dispôs sobre a competência da União para legislar sobre direito agrário, foi resultado das mobilizações sociais por reforma agrária. Posteriormente, foi aprovada a lei $\mathrm{n}^{\mathrm{o}} 4.504$, de 30/11/1964, que dispôs sobre o Estatuto da Terra, considerado um marco jurídico na luta pela reforma agrária no país.

Do conjunto dos grandes proprietários territoriais, o grupo composto por aqueles que usam a terra especialmente como reserva de valor e como arma de reprodução 
política é o único subsetor que deveria sair como definitivo e anunciado perdedor. Dessa forma poderíamos concordar que a atualidade da reforma agrária como "questão nacional”, voltada para o desenvolvimento agrário das últimas cinco décadas, deixou de existir no Brasil, e sua necessidade, nos dias atuais, está longe de qualquer patamar politicamente decisivo. Atualmente, Reforma agrária, apenas responde à oportunidade de aumentar o estoque de ocupações rurais, o que é determinante apenas em regiões determinadas (NAVARRO, 2001).

A concretização dos assentamentos de reforma agrária insere os trabalhadores, antes excluídos, ao quadro produtivo. Para isso, são necessárias linhas de crédito especiais, assistência técnica e investimentos em infraestruturas, voltadas à melhoria na produção e na qualidade de vida das famílias. Além da formação profisssional, outras políticas de desenvolvimento devem ser aplicadas logo após o assentamento dos trabalhadores. Instrumentos de política de desenvolvimento, como crédito, entre outros, devem ser aplicados imediatamente após o assentamento dos trabalhadores, além disso, a área deve ser imediatamente legalizada (SANTOS, 2001, p. 228)

Para Guanziroli et al. (2001, p. 55), “O financiamento destinado à agricultura também é distribuído de forma desproporcional entre os agricultores familiares e os patronais, sendo em todas as regiões inferior a participação dos estabelecimentos familiares no crédito rural". Santos (2001, p. 229) acrescenta que “a reforma agrária só terá sustentabilidade econômica e social se estiver inserida num contexto de políticas globais de valorização e ampliação do papel estratégico da agricultura em regime de economia familiar".

\subsection{Capital, Investimento e Inovação para a Agricultura}

De acordo com Santos (2001), uma agricultura familiar eficaz depende de alguns aspectos que combinam a economia familiar com novas tecnologias e diversificação dos meios de produção. Além disso, é preciso uma mudança radical no ambiente educacional frente às constantes mudanças do mundo, onde a tecnologia assume papel preponderante no desenvolvimento do sistema produtivo. Torna-se necessário uma maior integração entre ensino regular básico, formação profissional, redes de extensão rural, assistência técnica, todos voltados à pesquisa. Para compreender a forte concentração na produção agrícola brasileira, Vieira Filho $(2014$, p. 412) afirma que "é 
preciso avaliar não somente a distribuição tecnológica, como também a capacidade de absorção de conhecimentos".

O problema do desenvolvimento da agricultura tem proposto modelos de ação objetivando aumentar a produtividade dos fatores tradicionais, pela introdução de modificações tecnológicas possíveis por meio da adoção de inovações mais eficientes. Tais modificações, interagindo sobre os fatores tradicionais, aumentariam suas respectivas eficiências. Isso porque, apresentando uma produtividade marginal mais alta, ao serem combinadas com os fatores tradicionais, proporcionaria o crescimento da produtividade destes últimos (GREMAUD, 2006).

Segundo Costa (1995, p. 88), "o rendimento anual do trabalho da família camponesa influi nas decisões relativas ao emprego futuro da força de trabalho e das inovações técnicas que devem ou têm que ser incorporadas para o atingimento do equilíbrio otimizado".

Tendo em vista o progresso tecnológico (aplicado na indústria, por exemplo) torna-se necessário analisarmos essa modernização na agricultura. Guanziroli et al. (2001, p. 18) descreve esse processo dessa forma: "a questão da escala técnica da produção na agricultura ocupa papel central, e a importância do tema não pode ser minimizada."

$\mathrm{Na}$ medida em que vêm aumentando as despesas dos agricultores com manutenção e substituição de equipamentos, assim como para a aquisição e melhoramento de suas terras, a demanda por crédito rural torna-se cada vez mais crescente. O financiamento aos produtores, tradicionalmente, provinha de fontes particulares como comerciantes ou produtores rurais. Já o Crédito institucional foi introduzido em épocas recentes e a expansão do crédito rural tem evoluído a taxas relativamente altas, porém, apresentam elevadas taxas de endividamento (GUIMARÃES, 1982).

Sobre os aspectos tecnológicos e do crédito, Chayanov (1974) mostra que considerando um determinado nível de tecnologia e uma situação particular de mercado, uma família que controla seu espaço de terras aráveis pode maximizar o rendimento de sua força de trabalho e aumentar a intensidade de capital da exploração para o nível ideal para esta família. Um aumento forçado de intensidade de capital acima do nível ideal aumenta o volume do trabalho, e, inclusive, reduz o seu salário, já que por um lado, a elevação dos gastos para substituir o capital esgotado neutraliza o efeito positivo da intensificação do capital, e por outro, a realização econômica deste capital requer da 
unidade familiar a intensificação da sua força de trabalho mais do que o permitido pelo equilíbrio de fatores internos. Guanziroli et al. (2001, p. 261) explica que "o capital é escasso para os familiares e, portanto, usam menos desse insumo, fato oposto aos patronais, que podem desenvolver agricultura em grande escala graças à maior disponibilidade de capital".

Segundo Gazolla e Schneider (2007), a contribuição de Alexander Chayanov reside na concepção da unidade econômica camponesa como uma unidade de trabalho e também de consumo familiar. Sua concepção básica é de que o camponês realiza sua produção visando um equilíbrio ótimo entre consumo e trabalho da família, considerando, portanto, a composição e o tamanho da família e suas necessidades. Este balanço consumo/trabalho é influenciado por dois fatores. De um lado, a estrutura interna da família que determina as necessidades de consumo. De outro, o nível de produtividade da força de trabalho que é aplicado pela família. Assim, quanto maior for o número de consumidores da família e mais baixa for a produtividade da força de trabalho empregada no processo produtivo maior será o grau de auto exploração dos trabalhadores.

A perda da lucratividade estabelece, em detrimento da densidade de trabalho, progressivas aplicações de capital, aumentando a produtividade agrícola nas áreas de maior penetração capitalista. Apesar de algumas vantagens esse processo apresenta alguns aspectos negativos. O problema do aumento progressivo da intensidade de capital está em que ele corre paralelamente à concentração da propriedade e da renda no campo, a substituição de trabalhadores por máquinas que maximizam a produção, Dessa forma a agricultura vai perdendo a capacidade de geração de emprego e meio de vida, impossibilitando cada vez mais o acesso dos pequenos, médios produtores, assim como os assalariados rurais, que juntos formam a grande maioria da população do campo. (GUIMARÃES, 1982).

No início dos anos 90, que antecedeu a criação do PRONAF (Programa Nacional de Fortalecimento da Agricultura Familiar), a agricultura brasileira entrou num processo de desenvolvimento direcionado à abertura comercial, colocando os produtos brasileiros sob a concorrência do mercado internacional. $\mathrm{O}$ acesso ao crédito para os agricultores familiares era restrito em virtude de sua escassez. Alguns governos estaduais desenvolveram programas de financiamento com pagamento em equivalênciaproduto, mas, para a maioria dos que necessitavam de empréstimos para financiar a produção agrícola, restavam os financiamentos particulares em empresas cerealistas, 
cooperativas etc. A inflação e os juros altos que não estimulavam o aumento da produção por parte dos agricultores familiares e a intensificação do processo de abertura comercial consumia a renda agrícola (NUNES, 2007).

Outro financiamento na agricultura foi "o crédito do (Fundo Nacional de Financiamento do Norte) FNO, que se incorporou como um condicionante a mais da realidade camponesa, imiscuindo das mais diversas maneiras na vida econômica das famílias". (COSTA, 2000, p. 270).

Fala-se de uma função complementar da agricultura, que seria a de criar novos empregos no próprio meio rural. Dessa forma, programas governamentais procurariam não apenas fixar o homem no campo, como também proporcionar sua volta à agricultura, por meio de subsídios para irrigação, implantação de geradores de energia elétrica, compra de terras, investimentos em infraestrutura, etc. Programas de extensão rural e de incentivo ao cooperativismo e à formação de agroindústrias agiriam dessa mesma forma, promovendo a integração da agricultura com o setor urbano-industrial e o desenvolvimento rural (SOUZA, 2008).

De acordo com Veiga (2001), falta uma organização institucional para trabalhar nas articulações intermunicipais a fim de diagnosticar os principais problemas rurais de suas respectivas microrregiões, planejar ações de desenvolvimento integrado e captar os recursos necessários à sua execução. A proposta de Veiga (2001) é o encorajamento dos municípios rurais a se associarem e, assim, valorizarem o espaço que compartilham, fornecendo às associações os meios necessários ao desencadeamento do processo. Ou seja, o papel dos governos federal e estaduais deve ser o de estimular iniciativas que no futuro poderão ser autofinanciadas, mas que só surgirão se não houver o indispensável empurrão inicial.

\section{METODOLOGIA}

O objeto do presente estudo é o Projeto de Desenvolvimento Sustentável Bonal, localizado no município de Senador Guiomard - AC, estando a cerca de $60 \mathrm{~km}$ da sede municipal, criado através do processo $\mathrm{N}^{\circ} 021$, em 05/07/2005 e publicado através da Portaria $n^{\circ}$. 45/98 em 24/03/2005, com uma área aproximadamente de 10.447,80 hectares, com uma população em torno de 210 famílias.

\subsection{Caracterização do objeto de estudo}


Instituído através da Portaria n ${ }^{\circ} .21$ de 05 de julho de 2005, publicado no Diário Oficial da União nº. 132, de 12 de julho de 2005, Seção 1, pág. 90, o PDS Bonal possui uma área total de 10.447,80 ha (dez mil, quatrocentos e quarenta e sete hectares), está localizado no Estado do Acre, no município de Senador Guiomard à margem da BR364, km76 entre Rio Branco e Porto Velho-RO, conforme Figura 1, com capacidade para assentar 210 famílias.

\section{Figura 1 - Mapa de Localização do Projeto de Desenvolvimento Sustentável Bonal.}

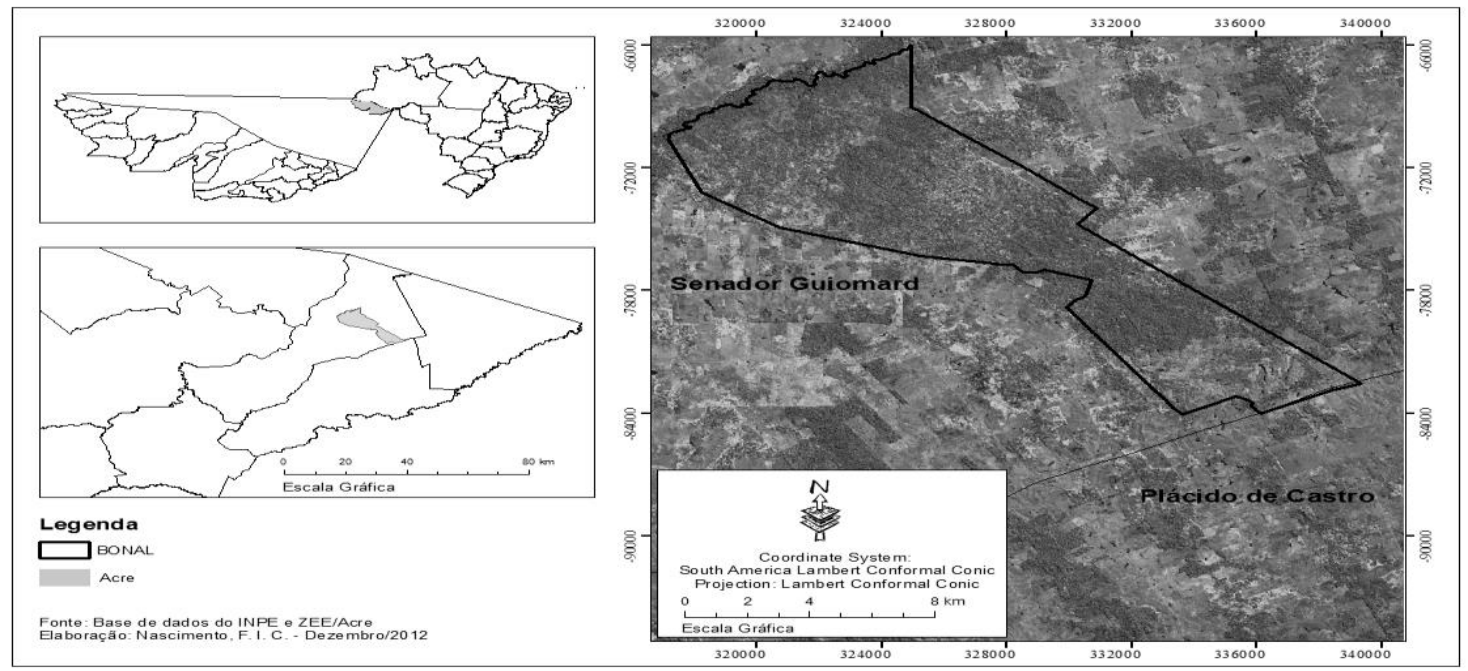

Fonte: Base de Dados INPE e ZEE/AC (2012).

Elaboração: Francisco Ivam Castro do Nascimento (2012).

De acordo com o INCRA (2010), a área do PDS Bonal foi adquirida pelo Governo Federal mediante processo da compra do local que pertencia a um grupo de empresários de origem Belga que desenvolviam, desde o início dos anos 1970, um projeto agroindustrial. A fazenda Bonal, como era conhecida na região, desenvolveu inicialmente o plantio racional de seringueiras para extração de látex. No início dos anos 1980, a empresa começou o plantio de pupunha para a produção de palmito e, em meados dos anos 1990, foi construída a agroindústria para o beneficiamento do palmito.

Após o processo de aquisição da área, o INCRA priorizou, inicialmente, o acesso à terra para as 41 famílias empregadas da antiga Fazenda Bonal. Na criação do PDS Bonal foi mantida a organização territorial original do imóvel que estava distribuída em três núcleos de moradia (agrovilas): Bom Destino, com 26 famílias, Morada Nova (Pista), com 14 famílias e a agrovila Retiro que, naquele momento possuía apenas uma família residente. A chegada das primeiras famílias que não faziam 
parte do quadro de empregados da antiga Fazenda Bonal, iniciou a partir do mês de outubro de 2005. Essas famílias, por sua vez, foram alocadas nas agrovilas já existentes.

No dia 15/07/2005, foi constituída a Cooperativa Agroextrativista Bom Destino LTDA - CAEB, designada a coordenar a exploração do palmito e a utilização da infraestrutura existente no assentamento. Segundo INCRA (2010), a CAEB inicialmente contava com 24 cooperados fundadores. No início de 2006 foi criado o Conselho Gestor da Cooperativa, órgão encarregado de representar os demais assentados e buscar soluções para os problemas.

\subsection{Amostragem}

No presente trabalho foi utilizada a mesma metodologia desenvolvida pelo projeto de pesquisa Análise Socioeconômica de Sistemas Básicos de Produção Familiar no Vale do Acre, denominado ASPF, desenvolvido pelo Centro de Ciências Jurídicas e Sociais Aplicadas da UFAC, desde $1996^{4}$, o qual faz uma análise sobre o desempenho econômico de unidades de produção familiares (UPF) no Estado do Acre.

O processo de levantamento de informações socioeconômicas é realizado por meio de amostragem, na qual foram sorteados aleatoriamente $10 \%$ dos produtores - do total de 210 assentados -, ponderados pela população assentada nos conglomerados existentes no PDS, sendo três agrovilas, além de produtores que moram na própria floresta do assentamento, o que resultou em 22 famílias entrevistadas.

\subsection{Coleta de dados}

Baseia-se, também, no trabalho de Costa (2007) que, ao trabalhar a dinâmica inovativa, considera o investimento como fator indispensável e define a propensão a investir como uma função da eficiência e tensão reprodutiva. Além disso, afirma que a disponibilidade de mão-de-obra determina as necessidades de investimento e formula um modelo baseado em três premissas:

Primeiro: a unidade produtiva camponesa tende a ser regulada em seu tamanho e em sua capacidade de mudar pela capacidade de trabalho que possui enquanto família. Sendo tal capacidade Ht, este montante tenderá a ser um limite tanto para garantir a reprodução como para empreender inovações. Essa premissa não é incompatível com a

\footnotetext{
${ }^{4}$ Ver https://aspf.wordpress.com/
} 
recorrência da contratação de força de trabalho externo à família, que sempre se constata empiricamente em universos camponeses.

Segundo: as forças que emergem das tensões contrárias - umas originadas das necessidades reprodutivas, que impulsionam ao trabalho, e outras provindas das tensões associadas ao próprio exercício do trabalho, estabelecem, pela experiência pessoal dos componentes da família e sua vivência cultural, um padrão reprodutivo, isto é, um hábito de consumo ajustado a uma rotina de trabalho.

Terceiro: as relações com os demais setores, que se faz por múltiplas mediações, algumas imediatas, outras mediatas, estabelecem as condições de realização de $\mathrm{He}$, do orçamento de reprodução. Assim, He realiza-se por $\mathrm{Hr}$, pelo dispêndio efetivo de trabalho dos membros da família, de modo que $\mathrm{Hr}$ é diferente, sendo, tendencialmente, maior ou igual a He e, necessariamente, menor ou igual a Ht. Trabalha-se, de fato, na unidade camponesa, em algum ponto entre o ponto de acomodação e o máximo de trabalho de que se poderia dispor.

De modo que:

1) Eficiência reprodutiva

$$
\left(\frac{H e}{H r}\right)=h
$$

Onde:

$\mathrm{h}=$ eficiência reprodutiva

$\mathrm{Hr}=$ volume de trabalho realmente despendido

$\mathrm{He}=$ valor das necessidades reprodutivas

O que estabelece a diferença entre $\mathrm{Hr}$ e $\mathrm{He}$ são as condições de permuta entre o trabalho despendido pelos membros da família, mediado pelas condições próprias das unidades produtivas, e o trabalho desenvolvido em outros ramos e setores da economia.

Quanto mais próximo $\mathrm{Hr}$ esteja de $\mathrm{He}$, mais eficientemente funciona o sistema, de sorte que a relação h é a sua mais importante medida de eficiência, a que se pode chamar de eficiência reprodutiva, grandeza que, necessariamente, varia entre 0 e 1 e expressa, observando-se pela ótica microeconômica, a capacidade do sistema de internalizar, reter em seu proveito, o trabalho por ele próprio despendido.

2) Tensão Reprodutiva - a eficiência reprodutiva não é imediatamente dada a perceber aos indivíduos que participam do sistema. Trata-se de fenômeno só sensorial ou intuitivamente perceptível pelos indivíduos através de seu efeito, a 
tensão reprodutiva. Formalmente, a tensão reprodutiva pode ser descrita como o inverso da eficiência reprodutiva e, assim,

$$
\left(\frac{H r}{H e}\right)=\frac{1}{h}=\partial
$$

Onde:

$\partial=$ Tensão reprodutiva

Trata-se de uma grandeza que expressa a tensão resultante do crescimento do volume de esforço físico e mental (Hr) para posição de consumo constante $(\mathrm{He})$.

A dinâmica inovativa do sistema resultaria, primeiro, da motivação de seus membros em despender o trabalho extraordinário que se faz necessário e, segundo, da disponibilidade efetiva (quer dizer, objetiva) de capacidade de trabalho para tanto. A motivação da família para investir, no modelo, está diretamente associada à distância de $\mathrm{Hr}$ (volume de trabalho realmente despendido) em relação a He (valor das necessidades reprodutivas), o que seria suficientemente descrita na relação $(\mathrm{Hr}-\mathrm{He}) / \mathrm{He}$. Por seu turno, a disponibilidade objetiva de energia para tanto é dada pela relação $(\mathrm{Ht}-\mathrm{Hr}) / \mathrm{Ht}-$ isto é, pela disponibilidade de trabalho potencialmente aplicável na inovação como uma proporção de Ht.

Multiplicada a primeira relação pela segunda, obtém-se:

$$
i=-\frac{H e}{H t} \cdot\left(\frac{1}{h}\right)^{2}+1+\left(\frac{1}{h}\right)-1
$$

Sendo:

$\mathrm{Ht}=$ capacidade de trabalho que possui enquanto família

A disposição ao investimento associada a capacidade de investir, i (a proporção do tempo de trabalho extraordinário que o conjunto dos membros da família provavelmente se disporá a alocar para formar elementos de capital, em relação ao tempo total de trabalho potencialmente utilizável), é uma função da tensão reprodutiva (o inverso da eficiência reprodutiva $h$ ) e percorre uma trajetória parabólica: seu valor tende a zero quando h tende a 1 (eficiência máxima e ponto de acomodação).

A implicação teórica disso é que, assumida a centralidade da reprodução, a racionalidade a ela atribuível pode explicar, ao mesmo tempo, 
(a) estados de baixa disposição para investir em situações muito favoráveis (em que $\mathrm{h}$ tende a 1, seu valor máximo) - ou avaliadas favoravelmente, de modo a não haver razões subjetivas para mudar;

(b) igualmente baixa disposição para investir em situações muito desfavoráveis, em que a condição objetiva básica para inovar, a disponibilidade de trabalho extra, de energia física e mental tende a zero e

(c) disposição a investir continuadamente elevada se o sistema se mantiver em posições relativamente equidistantes das posições extremas.

3) Índice de capitalização - é a relação que indica a intensidade de capital. É obtida pela fórmula:

$$
I K=\frac{K c}{V f t t}
$$

Sendo:

IK = índice de capitalização

$\mathrm{Kc}=$ capital constante

$\mathrm{Vftt}=$ valor total da força de trabalho empregada

$$
K c=(C c f+C i m+C m i)
$$

Sendo:

$\mathrm{Ccf}=$ custos de capitais fixos

4) Índice de trabalho familiar - é a participação da força de trabalho familiar no trabalho total. É dado pela relação:

$$
I T F=\frac{Q f t f}{Q f t t}
$$

Sendo:

ITF = índice de trabalho familiar

Qftf = quantidade anual da força de trabalho familiar empregada no sistema de produção $(\mathrm{h} / \mathrm{d})$

Qftt = quantidade anual total de força de trabalho empregada no sistema de produção $(\mathrm{h} / \mathrm{d})$

5) Índice de assalariamento - é a proporção da força de trabalho familiar que se assalaria fora da unidade de produção. É dado pela fórmula:

$$
I A=Q f t v(Q f t v \cdot Q f t f)
$$

Sendo:

$\mathrm{IA}=$ índice de assalariamento

Qftv = quantidade anual de força de trabalho vendida 
Qftf = quantidade anual de força de trabalho empregada no sistema de produção

Os índices: ITF, IK e IA, tomados individualmente ou no seu cruzamento, servirão para comparar os sistemas de produção quanto à categoria da unidade de produção (familiar ou empresarial) e dos produtores. Mais precisamente indicarão o lugar socioeconômico ocupado pelos produtores dos sistemas de produção pesquisados no espectro que vai desde o semiassalariado, a pequena produção simples (típica) e a empresa rural. Os índices mostrarão em que medida os produtores aproximam-se de um dos extremos ou mantém a sua autonomia de pequeno produtor.

Segue-se, aqui, o critério de Guerreiro (1994, p. 9) que estabelece os seguintes limites. Unidades de produção com ITF $\geq 50 \%$ e IK $\leq 2$ identificam pequenos produtores familiares. Supostos esses limites e IA > 20\%, o pequeno produtor decai no semiassalariado (camponeses pobres); Se IA $<20 \%$ e IK $<0,5$ o produtor está no limiar do semiassalariado; Com ITF $\geq 50 \%$ e $0,5 \leq \mathrm{Ik} \leq 2$, o produtor é pequeno produtor simples (camponês médio). Se ITF $\geq 50 \%$ e IK $>2$ fala-se de empresa familiar, os chamados "camponeses ricos". Se ITF $<50 \%$ e IK $>2$, o produtor é um empresário rural tecnificado; nas mesmas condições e IK $\leq 2$ trata-se de empresário rural não tecnificado.

\section{RESULTADOS E DISCUSSÕES}

As análises realizadas abrangem todas as culturas produzidas no PDS Bonal. Dentre elas destacam-se a produção de açaí, borracha, castanha e pupunha/palmito. A tabela1 mostra os índices de eficiência reprodutiva, tensão reprodutiva e propensão a investir da Unidade de Produção Familiar (UPF).

Tabela 1 - Números índices medianos das variáveis de reprodução no PDS Bonal, Senador Guiomard, Acre - 2012

\begin{tabular}{ccc}
\hline Eficiência reprodutiva (h) & Tensão reprodutiva $(\boldsymbol{\partial})$ & Propensão a investir (i) \\
\hline 2,22 & 0,45 & $-0,49$
\end{tabular}

Fonte: Elaboração própria.

De acordo com os parâmetros estudados um índice de eficiência reprodutiva (h) satisfatório tende a 0 , ou seja, o nível de trabalho aplicado é capaz de atender além das necessidades reprodutivas. Considerando uma Unidade em que satisfaz somente as necessidades reprodutivas esse índice é igual a 1. No PDS Bonal o índice de eficiência 
reprodutiva é maior que 2 . Isso significa que maior parte da renda das famílias é buscada fora da UPF.

Um maior nível de tensão reprodutiva $(\partial)$ significa mais pessoas da família trabalhando na produção em relação às necessidades reprodutivas. A mediana desse índice no PDS Bonal é de 0,45 , considerando que $\partial=1$ significa que a família está suprindo apenas suas necessidades reprodutivas, no estudo em questão em que $\partial<1$, a família não está suprindo suas necessidades reprodutivas na UPF, ou seja, o número de pessoas trabalhando na produção é insuficiente.

A propensão a investir (i) por sua vez mede a potencialidade da família em gerar valor além de suas necessidades reprodutivas, obtendo, pois, a capacidade de investir na produção em que o ponto ótimo tende a $\mathrm{i}=1$. No caso do PDS Bonal esse índice é de 0,49. Quando i < 0 a família não tem capacidade de investir com recursos da unidade caracterizando a falta de dinâmica inovativa de investimento, pois a produção da unidade não supre nem mesmo as necessidades reprodutivas.

A figura 2 mostra a propensão a investir (i) estratificada por grupos de acordo com a dinâmica reprodutiva da família em que, propensão a investir positiva $i>0$, propensão negativa $\mathrm{i}<0 \mathrm{e}$, propensão a investir considerada nula não há possibilidade nenhuma de investimento uma vez que nenhum membro da família trabalha na produção.

\section{Figura 2 - Propensão a investir do PDS Bonal, Senador Guiomard, Acre - 2012}

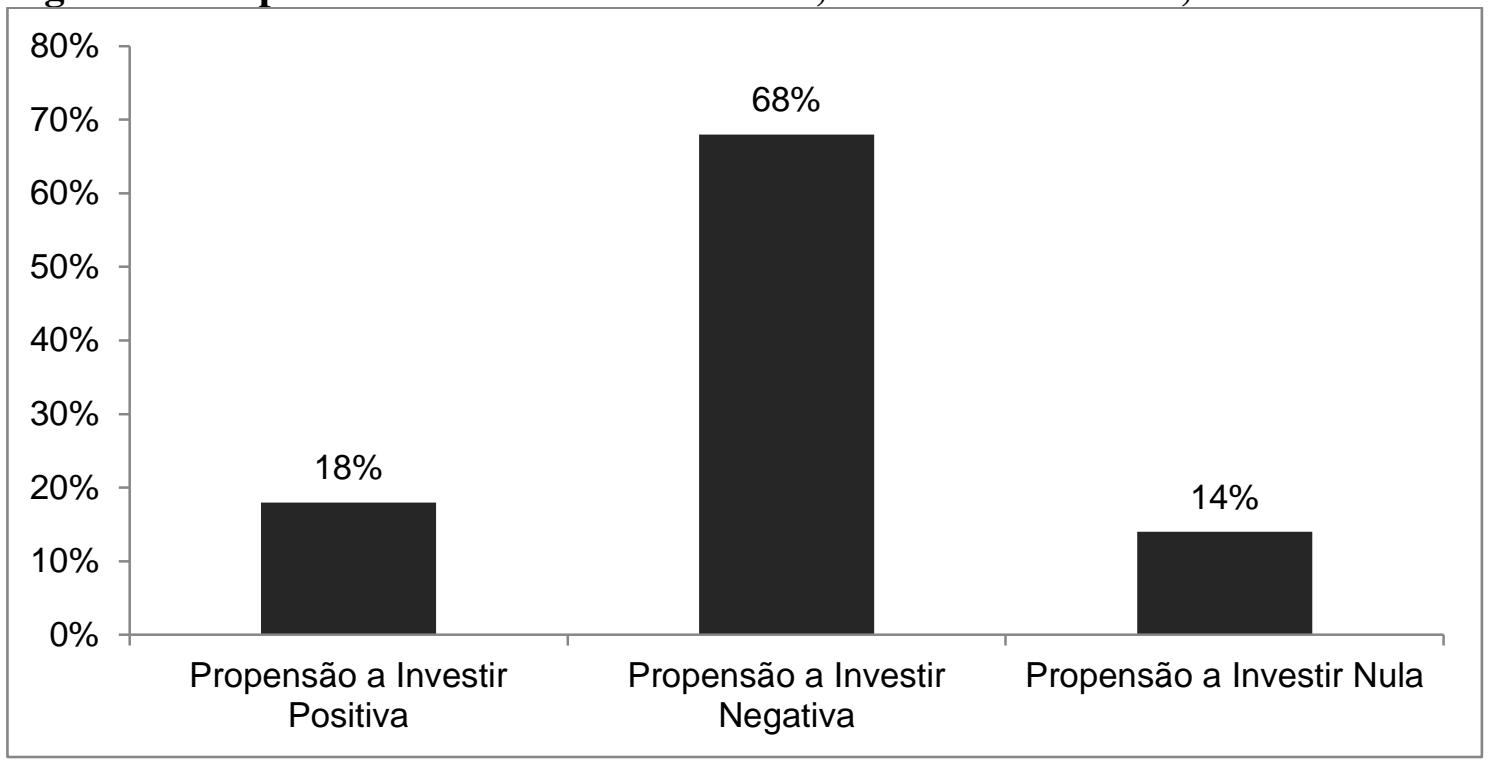

Fonte: Elaboração própria. 
Ainda na figura 2, observa-se que a maioria das famílias do PDS Bonal apresenta propensão a investir negativa, representando $68 \%$ do total. Esses resultados provêm de duas forças contrárias. Por um lado, o nível insatisfatório de eficiência reprodutiva (h), ou seja, as necessidades exigidas pelo autoconsumo e pelos bens comprados no mercado são muito elevadas, exercendo uma pressão sobre o valor da força de trabalho despendida na produção durante o mês. Por outro, a evasão da força de trabalho da unidade e o trabalho desocupado significam tensão reprodutiva ( $\partial$ ) baixa e exerce pressão contrária, distanciando cada vez mais a quantidade da força de trabalho total da força necessária para a reprodução básica das famílias.

Percebe-se também que apenas $18 \%$ das famílias do PDS Bonal apresentaram propensão a investir positiva, entende-se que essas famílias se dispõem de alguma dinâmica inovativa no sentido de investirem seus excedentes no processo produtivo. Essas famílias representam a capacidade que sua Unidade de Produção Familiar possui de gerar valor além de suas necessidades reprodutivas. Em contrapartida 14\% das famílias apresentaram propensão a investir nula, ou seja, famílias que não dedicam trabalho algum em sua unidade de produção. Dessa forma, suas necessidades são sanadas por outras fontes de renda, descaracterizando o sistema de produção familiar no qual estas famílias estariam inseridas, sistema este que propõe absorver a mão-de-obra das famílias ali assentadas, suprir as necessidades reprodutivas e, além disso, produzir dinâmica para o investimento.

Na figura 3 é apresentado o índice de trabalho familiar (ITF) no Projeto Bonal, uma das principais medidas que definem as características de uma unidade produtiva. Numa unidade de produção familiar, se considerado isoladamente, o ITF $\geq 50 \%$.

Figura 3 - Índice de trabalho familiar no Projeto Bonal, Senador Guiomard, Acre $-2012$

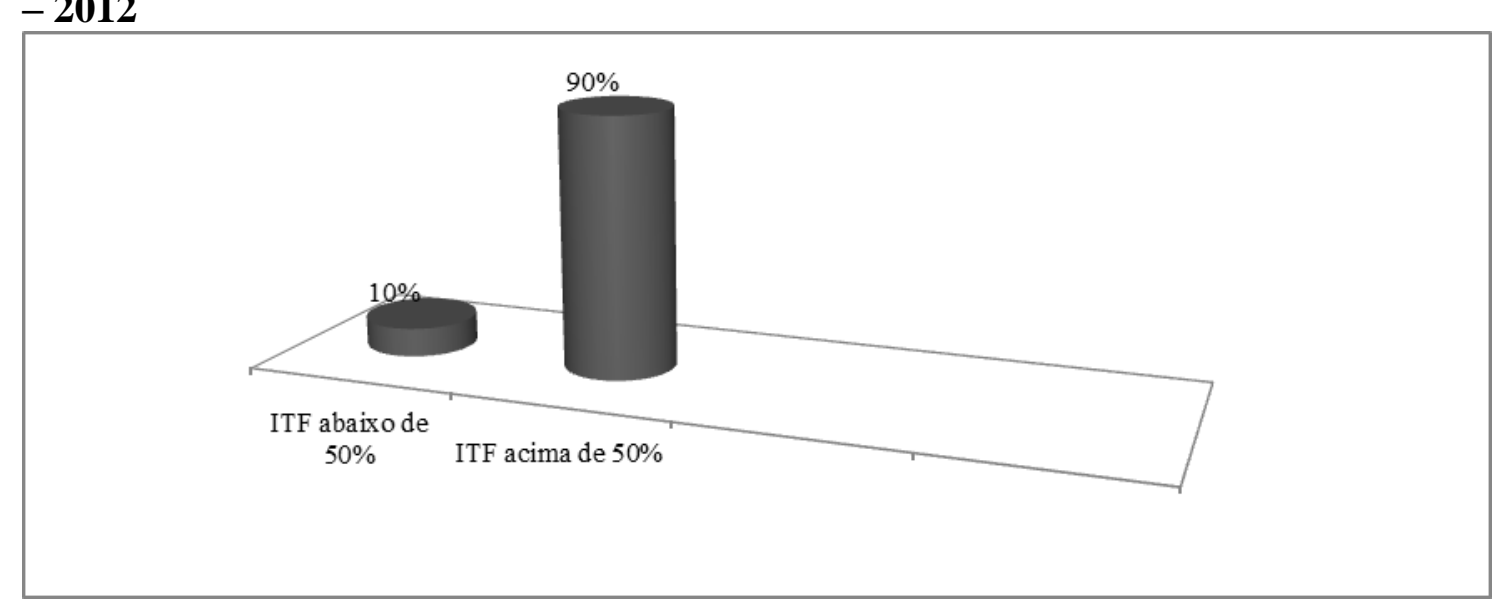

Fonte: Elaboração própria. 
No Projeto Bonal, $90 \%$ das UPFs têm ITF maior que 50\% e apenas $10 \%$ estão abaixo desse parâmetro, ou seja, no último grupo a maior parte do trabalho despendido na produção não é realizado pelos próprios produtores familiares. Porém, a análise apenas desse índice não é suficiente para a definição completa de uma unidade de produção, pois isso implicaria na rejeição de dois importantes índices na categorização da produção familiar rural, que são o índice de capitalização (IK), que indica a intensidade de capital, e o índice de assalariamento (IA), proporcionado pela força de trabalho que se assalaria fora da unidade de produção.

Na tabela 02, as características produtivas do PDS Bonal são apresentadas em termos medianos, consolidando ainda mais os resultados obtidos a partir da figura 3.

Tabela 2 - Números índices medianos das unidades de produção no PDS Bonal, Senador Guiomard, Acre - 2012.

\begin{tabular}{ccc}
\hline $\begin{array}{c}\text { Índice de Trabalho } \\
\text { Familiar (ITF) }\end{array}$ & $\begin{array}{c}\text { Índice de } \\
\text { Capitalização (IK) }\end{array}$ & Índice de Assalariamento (IA) \\
\hline 1,00 & 2,77 & 0,5 \\
\hline
\end{tabular}

Fonte: Elaboração própria.

A combinação dos índices indica que o produtor familiar mediano do PDS Bonal é semiassalariado intensivo em capital, evidenciando uma unidade produtiva intensiva em capital (IK > 2) e mão-de-obra ociosa no processo interno de produção, pois $50 \%$ da força de trabalho da unidade assalariam-se fora da unidade de produção. Nesse caso, o índice de trabalho familiar não é explicado pelo grande número de trabalhadores na produção e sim pela baixa capacidade produtiva.

Mesmo com elevados índices de trabalho familiar o PDS Bonal apresenta índices de capitalização e índices de assalariamento desfavoráveis, descaracterizando a produção familiar. De acordo com a Figura 4, apenas 5\% das UPFs são caracterizadas como efetiva produção familiar rural. Apesar de a maioria do trabalho ser realizada pelos próprios produtores, esse fator é fortemente pressionado pelo elevado índice de assalariamento proporcionado pela evasão da mão-de-obra interna que busca renda fora da unidade produtiva, caracterizando $30 \%$ das UPFs do PDS Bonal como produtores semiassalariados. 
Figura 4 - Perfil dos produtores do PDS Bonal, Senador Guiomard, Acre - 2012.

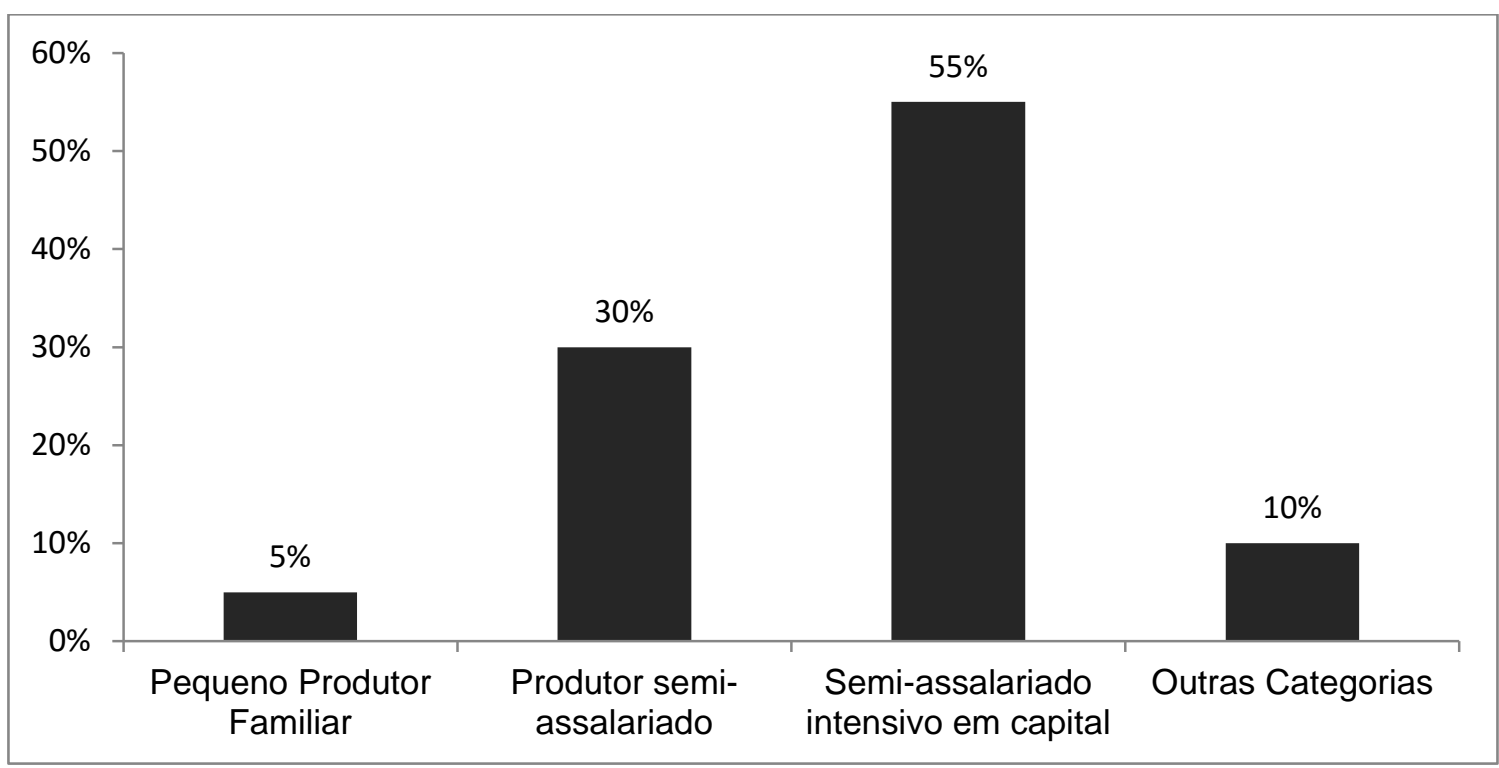

Fonte: Elaboração própria.

Ainda segundo a Figura 4, outro fator que descaracteriza o processo de produção familiar é o alto índice de capitalização (IK) observado no PDS Bonal que indica uma produção intensiva em capital, ou seja, os produtores gastam mais com capital fixo e circulante do que com mão-de-obra, e, até mesmo os gastos com capital são realizados com renda oriunda do trabalho externo, resultado dos elevados índices de assalariamento (IA). Dessa forma, além intensificar a forma de produção semiassalariada, torna-se mais intensiva em capital, representando $55 \%$ da unidade produtiva.

Considerando as características diversas de produtores diagnosticadas no PDS Bonal, a tabela 03 mostra o desempenho dos perfis das famílias a partir de indicadores reprodutivos.

Tabela 3 - Mediana dos indicadores reprodutivos entre as famílias de acordo com os perfis de produção, Senador Guiomard, Acre - 2012

\begin{tabular}{cccc}
\hline Perfil da produção & $\begin{array}{c}\text { Eficiência } \\
\text { reprodutiva }(\mathbf{h})\end{array}$ & $\begin{array}{c}\text { Tensão reprodutiva } \\
(\boldsymbol{\partial})\end{array}$ & $\begin{array}{c}\text { Propensão a investir } \\
(\mathbf{i})\end{array}$ \\
\hline Produção familiar & 0,69 & 1,46 & 0,12 \\
Semi-assalariado & 2,59 & 0,39 & $-0,55$ \\
Semi-assalariado & 2,55 & 0,39 & $-0,55$ \\
intensivo em capital & & & \\
\hline
\end{tabular}

Fonte: Elaboração própria. 
No tocante aos índices reprodutivos dos principais perfis de produtores detectados no Projeto Bonal, observa-se que os pequenos produtores familiares apresentam eficiência reprodutiva menor que $1(\mathrm{~h}=0,69)$, representando uma capacidade de produzir em sua unidade acima das necessidades reprodutivas. O nível de tensão reprodutiva na produção familiar também mostra resultados satisfatórios, uma vez que atinge um nível maior que $1(\partial=1,46)$, ou seja, tais unidades empenham mãode-obra suficiente no processo produtivo em relação à quantidade necessária para suprir as necessidades. Índices de eficiência e tensão reprodutivas favoráveis resultam em propensão a investir positiva que, por sua vez, representam a capacidade e a disponibilidade das famílias em investirem em sua UPF. Assim, todas as famílias que se enquadram no perfil de produtores familiares no PDS Bonal têm propensão a investir positiva (acima de zero) (tabela 04).

A maioria das famílias do PDS Bonal, conforme a tabela 03, enquadra-se no perfil de produção semiassalariada simples ou intensiva em capital. Nestas categorias o índice de eficiência reprodutiva revelado está a mais de $150 \%$ acima do nível mínimo aceitável. Além disso, a tensão reprodutiva abaixo de $1(\partial=0,39)$ retrata a insuficiência de mão-de-obra despendida na unidade familiar. A consequência de índices de eficiência e tensão reprodutivas insatisfatórios é uma propensão a investir negativa.

Ao avaliar os indicadores reprodutivos os resultados sugerem a exposição proporcional do desempenho das famílias no tocante à propensão a investir de acordo com os perfis observados, considerando que na propensão a investir nula não existe dispêndio de trabalho algum na unidade de produção. (ver tabela 04).

Tabela 4 - Propensão a investir entre as famílias de acordo com o perfil do produtor, Senador Guiomard, Acre - 2012.

\begin{tabular}{cccc}
\hline $\begin{array}{c}\text { Perfil da } \\
\text { produção }\end{array}$ & $\begin{array}{c}\text { Propensão a } \\
\text { investir positiva } \\
(\boldsymbol{\%})\end{array}$ & $\begin{array}{c}\text { Propensão a investir } \\
\text { negativa }(\boldsymbol{\%})\end{array}$ & $\begin{array}{c}\text { Propensão a } \\
\text { investir nula } \\
(\boldsymbol{\%})\end{array}$ \\
\hline Produção familiar & 100 & - & - \\
$\begin{array}{c}\text { Semi assalariado } \\
\text { Semi assalariado } \\
\text { intensivo em } \\
\text { capital }\end{array}$ & 17 & 83 & - \\
Outras categorias & 18 & & - \\
\hline
\end{tabular}

Fonte: Elaboração própria. 
No Projeto Bonal, apesar de representar apenas 5\% do perfil das famílias, todos que se enquadram como pequenos produtores familiares apresentam propensão a investir positiva, demonstrando que possuem capacidade reprodutiva e, além disso, estão dispostos a investir em sua unidade familiar, uma vez que aplicam trabalho para satisfazer além de suas necessidades básicas.

No perfil semiassalariado os resultados são inviáveis, considerando que a propensão a investir positiva representa $17 \%$ das famílias, ou seja, mais de $80 \%$ dos trabalhadores semiassalariados, simples ou intensivos em capital, têm propensão a investir negativa, não produzem o suficiente para suprir os gastos com sua unidade produtiva, pois sua capacidade de trabalho encontra-se empregada em outras atividades.

No PDS Bonal foram detectados, também, proprietários que não se enquadram em nenhuma das categorias mencionadas, porém, estão classificados como outras categorias. Metade daqueles que apresentam esse perfil têm propensão a investir negativa, nos outros $50 \%$ essa propensão é nula. Tais resultados justificam-se pela não aplicação de mão-de-obra no processo produtivo, aqui a terra é utilizada para outras finalidades como o lazer ou, até mesmo, para especulação.

\section{Conclusão}

A partir da década de 70 a implantação de políticas públicas desenvolvimentistas para a Amazônia, em especial no Acre, trouxe um aumento na desagregação das atividades econômicas tradicionais e na exploração dos recursos regionais, ocasionando uma grande alteração nos ecossistemas locais. Essas políticas também foram responsáveis pelo tipo de ocupação e uso da terra que agravou o processo de degradação social e ambiental, levando a vários conflitos fundiários e luta pela terra na região Amazônica e no Acre, em particular. Neste contexto, surgem os Projetos de Assentamentos Dirigidos - PAD's, como proposta de amenizar os conflitos de terra na região.

O principal objetivo dos movimentos sociais e dos programas relacionados a uma reforma agrária é a redistribuição mais equitativa da terra, proporcionando aos trabalhadores a realização de suas necessidades reprodutivas, a produção de bens primários para o mercado através da produção agrícola familiar e uma função complementar da agricultura, que seria a de criar novos empregos no próprio meio rural. 
Dessa forma, programas governamentais procurariam não apenas fixar o homem no campo como também proporcionar sua volta à agricultura, por meio de subsídios e investimentos em infraestrutura. Programas de extensão rural e de incentivo ao cooperativismo e à formação de agroindústrias promoveriam a integração da agricultura com o setor urbano-industrial e o desenvolvimento rural.

A partir dos conceitos e objetivos da produção familiar, pode-se fazer um diagnóstico da situação do PDS Bonal como unidade produtiva. O trabalho ocioso representado por baixos níveis de tensão reprodutiva, associado à incapacidade de investir no processo produtivo a partir do trabalho despendido na própria produção, desclassifica os lotes do PDS Bonal como espaço com efetiva produção familiar rural. Ao contrário, os lotes que deveriam ser unidades produtivas familiares são caracterizados, em sua maioria, como unidades de trabalhadores semiassalariados, contrariando o principal objetivo da criação dos Projetos de Desenvolvimento Sustentável, a autosustentabilidade.

O PDS Bonal, a exemplo dos outros projetos de assentamentos realizados na Amazônia, apresenta características semelhantes no que diz respeito à distribuição de terras e permanência dos assentados em suas unidades produtivas.

Porém, um dos problemas encontrados no PDS Bonal está relacionado à classificação das famílias ao serem assentadas no PDS. Boa parte destas famílias não trazia o conhecimento em produção agrícola familiar, tampouco, receberam assistência técnica suficiente. Dessa forma, alguns moradores passaram a realizar atividades não agrícolas, outros, a buscar opções de renda fora da UPF.

a partir dos resultados que as unidades produtivas caracterizadas com o perfil de produção familiar podem ser viáveis do ponto de vista reprodutivo e dinâmica inovativa, dada a propensão positiva a investir na produção. Porém, a maioria dos produtores do PDS Bonal não se enquadra nesse perfil, não apresentando dinâmica inovativa de investimento, uma vez que unidades de produção criadas com a finalidade de desenvolver o sistema de produção familiar não se adaptam a outras formas de produção, pela sua inviabilidade reprodutiva nesse ambiente. 
Referências

ABRAMOVAY, Ricardo. Um novo contrato para a política de assentamentos. In: OLIVEIRA, Pedro M., (org.). 2005. Economia Brasileira - Perspectivas do Desenvolvimento - Ed. CAVC, São Paulo - pp. 355-375.

CHAYANOV, A. La Organización de La Unidad Económica Campesina. Buenos Aires, 1974.

COSTA, F. A. - Formação Agropecuária da Amazônia: os desafios do desenvolvimento sustentável. Belém: UFPA/NAEA, 2000.

O investimento na Economia camponesa: considerações teóricas. Revista de Economia Politica, vol. 15, nº 1 (57), Janeiro-março/1995.

A Dinâmica Peculiar dos Investimentos Agrícolas nos Estados Unidos (1948-1994): Uma Explicação Baseada em Eficiência Reprodutiva. Economia, Brasília (DF), v.8, n.2, p. 289-320, maio/agosto 2007.

FAVARETO, A. S.. Paradigmas do desenvolvimento rural em questão. 1. ed. São Paulo: Fapesp/Iglu, 2007. v. 1. 220p.

FURTADO, C. Introdução ao desenvolvimento: enfoque histórico-estrutural. 3. Ed. Rio de Janeiro: Paz e Terra, 2000.

GASQUES, J. G; FILHO, E. R.V; NAVARRO, Z. A Agricultura Brasileira: desempenho, desafios e perspectivas. Brasília: Ipea, 2010.

GAZOLLA, M.; SCHNEIDER, S.. A produção da autonomia: os "papéis" do autoconsumo na reprodução social dos agricultores familiares. Rio de Janeiro: Estud. Soc. Agric, v.15, nº 1, p. 89-122, 2007.

GREMAUD, A, P.; PINHO, D. B.; VASCONCELOS, M. A. S. de. Manual de Economia. 5. ed. São Paulo: Saraiva, 2006.

GUANZIROLI, C.; ROMEIRO, A; SABBATO, A. di; BUAINAIN, A. M.; BITTENCOURT, G. (Orgs.). Agricultura Familiar e Reforma Agrária no Século XXI. Rio de Janeiro: Garamond, 2001.

GUIMARÃES, A. P. A Crise Agrária. $3^{\text {a }}$ ed. Rio de Janeiro: Paz e Terra, 1982.

INCRA - Instituto Nacional de Colonização e Reforma Agrária. Histórico da questão agrária. 2010. Disponível em: <http://www.incra.gov.br/index.php/reforma-agraria2/questao-agraria/historico-da-questao-agraria>. Acesso em: 20/11/2014.

MELO, J. A. T. (Org.). Reforma agrária quando? CPI mostra as causas da luta pela terra no Brasil. Brasília: Senado Federal, p. 57, 2006. 
NAVARRO, Z. Desenvolvimento rural no Brasil: os limites do passado e os caminhos do futuro. Estudos Avançados, São Paulo, v. 15, n. 43, p. 83-100, set./dez. 2001.

NUNES, S. P. O crédito rural do Pronaf e os recentes instrumentos de política agrícola para a agricultura familiar. Deser-Boletim Eletrônico, n.156, 2007.

OSZLAK, O. Reforma Agraria en La America Latina: Uma aproximacion política. Revista Internacional de Desenvolvimento Comunitário. Piazza Cavalieri di Malta, 2- Roma, 1971.

SANTOS, M. J. Projeto alternativo de desenvolvimento rural sustentável. Estudos Avançados [online], vol.15, n.43, p. 225-238, 2001.

SOUZA, N. J. Desenvolvimento Econômico. 5. Ed. 3. Reeimp. São Paulo: Atlas, 2008.

VEIGA, J. E. O Brasil rural ainda não encontrou seu eixo de desenvolvimento. Estudos Avançados, São Paulo, v. 15, n. 43, p. 101-119, set./dez. 2001.

VIEIRA FILHO, José Eustáquio Ribeiro. Transformação histórica e padrões tecnológicos da agricultura brasileira. In: BUAINAIN, A. M; ALVES, E; SILVEIRA, J. M. da; NAVARRO, Z. (Ed. técnico). O mundo rural no Brasil do século 21: a formação de um novo padrão agrário e agrícola. Brasília: EMBRAPA, 2014.

WANDERLEY, Maria de Nazareth Baudel. Raízes históricas do campesinato brasileiro. In: TEDESCO, J.C. (Org.). Agricultura familiar: realidades e perspectivas. Passo Fundo: EDIUPF, 394 p, 2001. p. 23-56.

Submetido em: 23/09/15

Aceito em: 04/04/16 